\title{
Effect of four days of preoperative lactulose on posthaemorrhoidectomy pain: results of placebo controlled trial
}

\author{
N J M LONDON, P D BRAMLEY, R WINDLE
}

\begin{abstract}
The effect of four days of preoperative lactulose on posthaemorrhoidectomy pain was studied in a prospective double blind randomised trial. All patients received lactulose on admission to hospital, 20 received lactulose for four days before admission, and 22 received placebo.

The preoperative lactulose treatment group suffered signifcantly less pain on defecation for the first four days that they opened their bowels (visual analogue scores in cm: day $1,4.4 \mathrm{v}$ 5.9; day $2,4.1$ v 6.3; day $3,4.5$ v 6.1; day $4,4.6$ v 6.5), suffered significantly less pain during the first two 24 hour periods after defecation (visual analogue scores in $\mathrm{cm}$ : day $1,5.0 \mathrm{v} 7.0$; day 2 , 3.9 v 6.1), and required significantly less analgesia daily after defecation $(0.76 \mathrm{~g}$ paracetamol/day $\mathrm{v} 1.29 \mathrm{~g}$ paracetamol/day).

These results show that lactulose given for four days preoperatively reduces pain after haemorrhoidectomy.
\end{abstract}

\section{Introduction}

It is common practice to prescribe laxatives at the time of admission for patients admitted for haemorrhoidectomy. Nevertheless, because patients are starved for operation the next day many patients receive only a single dose preoperatively. In this study of posthaemorrhoidectomy pain we have compared the effect of lactulose taken from the time of admission to hospital with lactulose taken from four days before operation.

\section{Patients and methods}

A prospective, randomised double blind study was designed to include all patients, except diabetics, listed for haemorrhoidectomy by eight consultant surgeons. The trial received approval from the local ethical committee. The rationale of the study was explained to patients in the outpatient department, at which time they were invited to participate. The 42 patients who agreed to the trial received a numbered bottle containing either lactulose or placebo. Patients received written instructions from the pharmacy explaining that they should take $15 \mathrm{ml}$ of the liquid three times daily for four days before their operation. These doses were recorded by the patients as they took them.

All patients received $15 \mathrm{ml}$ lactulose three times daily from the time of admission to hospital until discharge. Patients were premedicated with papaveretum and hyoscine in appropriate doses. General anaesthesia was standardised to thiopentone, oxygen, nitrous oxide, and halothane. Caudal block, anal stretch, and infiltration with local anaesthetic were not used. Postoperative analgesia was provided by intramuscular papaveretum or oral paracetamol.

Postoperative pain was assessed from the end of the first postoperative day by using verbal response and visual analogue scales. The verbal response scales had four options-no pain, mild pain, moderate pain, and severe pain. The visual analogue scale consisted of a $10 \mathrm{~cm}$ line with the words "no pain" on the left hand side and "worst pain imaginable" on the right. Two

Department of Surgery, Glenfield General Hospital, Leicester LE3 9QP N J M LONDON, MRCP, FRCS, surgical registrar P D BRAMLEY, MSCPHARM, pharmacist R WINDLE, MD, FRCS, consultant surgeon

Correspondence to: Mr N J M London, Department of Surgery, Clinical Sciences Building, University of Leicester, PO Box 65, Leicester LE2 7LX. types of pain were assessed, pain on defecation and pain during the preceding 24 hours. The scales for pain on defecation were completed immediately after defecation and the scales for 24 hour pain completed each evening. In order that pain could be assessed for seven postoperative days patients were given forms to complete at home and return to the hospital. Patients were discharged from hospital at the discretion of their consultants, none of whom had a discharge policy for patients after haemorrhoidectomy. At the conclusion of the study the numbered bottle code was broken and the results analysed.

The visual analogue scores were measured in $\mathrm{cm}$, the score for each 24 hours being a single value. The score for pain on defecation for any one day was the mean value of scores during that day. Statistical methods used were Student's $t$ test, the Mann-Whitney U test, and the $\chi^{2}$ test with Yates's correction. Differences at $p<0.05$ were considered to be significant.

\section{Results}

Twenty patients were randomised to receive four days of lactulose preoperatively and 22 to receive placebo. The two groups were well matched for age, sex, numbers of haemorrhoids excised, and status of the surgeon (table I). The lactulose treated group defecated earlier $(p=0.01)$, had more frequent bowel actions in the first postoperative week $(p=0.05)$, and had a shorter hospital stay $(p=0.03)$ compared with the placebo group (table II).

TABLE I-Details of patients studied

\begin{tabular}{lcc}
\hline & Lactulose group & Placebo group \\
\hline No of patients & 20 & 22 \\
$\quad$ Men/women & $13 / 7$ & $17 / 5$ \\
Mean age (years) (SD) & $47 \cdot 4(10 \cdot 6)$ & $49 \cdot 4(14 \cdot 6)$ \\
No of haemorrhoids excised: & & \\
$\quad$ Three & 16 & 17 \\
$\quad$ Two & 4 & 5 \\
Status of surgeon: & 2 & 3 \\
$\quad$ Consultant & 8 & 7 \\
$\quad$ Registrar & 10 & 12 \\
\hline
\end{tabular}

TABLE II-Postoperative course of treatment groups

\begin{tabular}{|c|c|c|}
\hline & $\begin{array}{l}\text { Lactulose } \\
\text { group }\end{array}$ & $\begin{array}{l}\text { Placebo } \\
\text { group }\end{array}$ \\
\hline $\begin{array}{l}\text { Median hospital stay (days) (range) } \\
\text { Median time to first bowel action (days) (range) } \\
\text { Median No of bowel actions in first week (range) }\end{array}$ & $\begin{array}{l}5(3-8)^{\star} \\
2(1-3) \dagger \\
9(1-13)+t\end{array}$ & $\begin{array}{l}5(4-14) \\
3(1-6) \\
6(2-10)\end{array}$ \\
\hline
\end{tabular}

^ $p=0.03$ (Mann-Whitney U test).

t $\mathrm{p}=\mathbf{0 . 0 1}$ (Mann-Whitney $U$ test).

H $p=0.05$ (Mann-Whitney U test).

Pain before defecation-The lactulose and placebo treatment groups experienced similar degrees of pain before their first bowel action, as assessed by both visual analogue and verbal response scales (tables III and IV).

Pain on defecation-The lactulose treatment group experienced significantly less pain on defecation than the control group for the first four days that they opened their bowels as assessed by visual analogue scales, and the first three days as assessed by verbal response scales (tables V and VI). Analysis of the visual analogue scales for the 24 hour periods after defecation showed that the lactulose treated group experienced less pain during the first two 24 hour periods $(5 \cdot 0$ (SD 1.8) $\mathrm{cm} v 7.0(2 \cdot 2) \mathrm{cm}$ and $3.9(2 \cdot 1) \mathrm{cm} v 6.1$ $(2.4) \mathrm{cm} ; \mathrm{p}=0.005$ ( $t$ test $))$. The verbal response scales for the 24 hour 
periods after defecation showed that the lactulose treated group experienced less pain during the first 24 hour period (4/20 severe pain $v$ 13/22 severe pain; $\mathrm{p}=0.03\left(\chi^{2}\right.$ test $)$ ).

Analgesic requirements of the two groups before defecation did not differ significantly $(0.27($ SD 0.30$) \mathrm{mg}$ papaveretum $/ \mathrm{kg} /$ day $v 0.24(0.27) \mathrm{mg}$ papaveretum $/ \mathrm{kg} /$ day, and $0.82(0.74) \mathrm{g}$ paracetamol/day $v 0.92(0.68) \mathrm{g}$ paracetamol/day). The lactulose treated group required significantly less paracetamol daily after defecation had begun than did the placebo group $(0.76(0.54) \mathrm{g} /$ day $v 1.29(0.51) \mathrm{g} /$ day; $\mathrm{p}<0.01(t$ test $))$.

\section{Discussion}

Porter compared lactulose with a magnesia and paraffin emulsion taken from the time of admission by patients admitted for haemorrhoidectomy and found that the patients given lactulose defecated earlier and had less pain at the first postoperative bowel action. ${ }^{1}$ Lactulose may take up to 48 hours to produce an effect in some patients. This, taken in conjunction with the fact that many patients who are prescribed lactulose on admission do not actually receive a preoperative dose, led us to examine the effect of four days of preoperative lactulose on posthaemorrhoidectomy pain.

Postoperative pain is difficult to assess, though verbal response scales $^{2}$ and visual analogue scales ${ }^{3}$ are recognised methods. Maxwell concluded that the $t$ test is "very robust" when comparing differences between visual analogue scale scores, ${ }^{4}$ and we therefore used this method of analysis. On two occasions the verbal response scale detected differences in pain for a day less than the visual analogue scale. This is to be expected because the discrete verbal response scale is less sensitive than the continuous visual analogue scale.

TABLE III-Twenty four hour pain experienced by treatment groups before first bowel action. Results expressed as mean visual analogue scores (cm) (SD in parentheses). [Numbers of patients not opened bowels by stated day given in square brackets]

\begin{tabular}{lcccccc}
\hline \multicolumn{7}{c}{ Postoperative day } \\
\cline { 2 - 7 } & 1 & 2 & 3 & 4 & 5 & 6 \\
\hline Lactulose group & $4 \cdot 9(2 \cdot 1)^{\star}$ & $4 \cdot 8(1 \cdot 2)^{\star}$ & $3 \cdot 2$ & -2 & - & - \\
Placebo group & {$[15]$} & {$[5]$} & {$[1]$} & {$[0]$} & {$[0]$} & {$[0]$} \\
& $5 \cdot 0(2 \cdot 4)$ & $3 \cdot 4(1 \cdot 9)$ & $1 \cdot 1(0 \cdot 7)$ & $1 \cdot 8(2 \cdot 6)$ & $0 \cdot 4$ & $0 \cdot 4$ \\
& {$[19]$} & {$[12]$} & {$[4]$} & {$[3]$} & {$[1]$} & {$[1]$} \\
\hline
\end{tabular}

^Not significant compared with placebo group (Student's $t$ test).

TABLE IV-T.wenty four hour pain experienced by treatment groups before first bowel action. Figures are numbers of patients with severe pain as assessed by verbal response scores. [Numbers of patients not opened bowels by stated day given in square brackets]

\begin{tabular}{lccccccc}
\hline & \multicolumn{7}{c}{ Postoperative day } \\
\cline { 2 - 7 } & & 1 & 2 & 3 & 4 & 5 & 6 \\
\hline Lactulose group & $4^{\star}$ & $1^{\star}$ & 0 & $\bar{y}$ & $\bar{y}$ & $\bar{y}$ \\
Placebo group & {$[15]$} & {$[5]$} & {$[1]$} & {$[0]$} & {$[0]$} & {$[0]$} \\
& 8 & 0 & 0 & 0 & 0 & 0 \\
& {$[19]$} & {$[12]$} & {$[4]$} & {$[3]$} & {$[1]$} & {$[1]$} \\
\hline
\end{tabular}

^Not significant compared with placebo group $\left(\chi^{2}\right.$ test).
TABLE V-Pain on defecation experienced by treatment groups. Results expressed as mean visual analogue scores (cm) (SD in parentheses). [Numbers of patients who opened bowels on stated day given in square brackets]

\begin{tabular}{lccccccc}
\hline \multicolumn{7}{c}{ Day of bowel action } \\
\cline { 2 - 8 } & 1 & 2 & 3 & 4 & 5 & 6 & 7 \\
\hline Lactulose group & $\begin{array}{c}4 \cdot 4(1 \cdot 8) \\
{[20]}\end{array}$ & $\begin{array}{c}4 \cdot 1(1 \cdot 8) \\
{[19]}\end{array}$ & $\begin{array}{c}4 \cdot 5(2 \cdot 4) \\
{[19]}\end{array}$ & $\begin{array}{c}4 \cdot 6(2 \cdot 5) \\
{[18]}\end{array}$ & $\begin{array}{c}4 \cdot 3(2 \cdot 7) \\
{[17]}\end{array}$ & $\begin{array}{c}4 \cdot 6(3.0) \\
{[12]}\end{array}$ & $\begin{array}{c}2 \cdot 6(1 \cdot 7) \\
{[4]}\end{array}$ \\
Placebo group & $\begin{array}{c}5 \cdot 9(2 \cdot 8) \\
{[22]}\end{array}$ & $\begin{array}{c}6 \cdot 3(2 \cdot 3) \\
{[21]}\end{array}$ & $\begin{array}{c}6 \cdot 1(2 \cdot 0) \\
{[20]}\end{array}$ & $\begin{array}{c}6 \cdot 5(1 \cdot 6) \\
{[14]}\end{array}$ & $\begin{array}{c}5.9(2 \cdot 7) \\
{[10]}\end{array}$ & $\begin{array}{c}4 \cdot 7(2 \cdot 4) \\
{[7]}\end{array}$ & $\begin{array}{c}6 \cdot 1(3 \cdot 3) \\
{[3]}\end{array}$ \\
\hline p Value ( $t$ test) & 0.05 & 0.025 & 0.05 & 0.02 & NS & - & - \\
\hline
\end{tabular}

Table refers to day of bowel action, not postoperative day. All patients followed up for seven postoperative days; thus patient who first opened bowels on postoperative day 3 appears in table for five days of bowel action.

TABLE VI-Pain on defecation experienced by treatment groups. Figures are numbers of patients with severe pain as assessed by verbal response scores. [Numbers of patients who opened bowels on stated day given in square brackets]

\begin{tabular}{lccccccc}
\hline \multicolumn{7}{c}{ Day of bowel action } \\
\cline { 2 - 9 } & 1 & 2 & 3 & 4 & 5 & 6 & 7 \\
\hline Lactulose group & 4 & 4 & 2 & 4 & 2 & 2 & 1 \\
Placebo group & {$[20]$} & {$[19]$} & {$[19]$} & {$[18]$} & {$[17]$} & {$[12]$} & {$[4]$} \\
& 13 & 13 & 9 & 5 & 3 & 1 & 0 \\
& {$[22]$} & {$[21]$} & {$[20]$} & {$[14]$} & {$[10]$} & {$[7]$} & {$[3]$} \\
\hline pValue $\left(\chi^{2}\right.$ test $)$ & 0.03 & 0.025 & 0.04 & NS & NS & - & - \\
\hline
\end{tabular}

The lactulose and placebo treatment groups experienced similar amounts of pain during the 24 hour periods before they opened their bowels. The lactulose treated group had significantly less pain on defecation for the first four days that they had a bowel action. This reduced pain on defecation was reflected in reduced pain during the first two 24 hour periods after defecation began. This is important because it shows that the increased frequency of bowel action in the lactulose treated group did not result in an increase in the total pain perceived during the postoperative period.

This study has shown that four days of preoperative lactulose reduces posthaemorrhoidectomy pain. We therefore suggest that this regimen should be part of the routine preparation of patients for haemorrhoidectomy.

We thank the consultant surgeons at the Leicester Royal Infirmary for allowing us to study patients under their care, the nursing staff, the department of anaesthesia, for their cooperation, and the pharmacy for providing the placebo. Our thanks are also due to Mr D Shaw, statistician, of the department of ophthalmology, University of Leicester.

\section{References}

1 Porter N. The use of lactulose in posthaemorrhoidectomy patients. Br $\mathcal{F}$ Clin Pract 1975;29:235-6. 2 Hewer AJH, Keele CA. A method of testing analgesics in man. Lancet 1948;i:683-8.

3 Bond MR, Pilowsky I. Subjective assessment of pain and its relationship to the administration of analgesia in patients with advanced cancer. $\mathcal{F}$ Psychosom $R$ es 1966;10:203-8.

4 Maxwell C. Sensitivity and accuracy of visual analogue scale: a psycho-physical classroom experiment. Br J Clin Pharmacol 1978;6:15-24.

(Accepted 5 fune 1987) 